\title{
Taking the 'sauer' out of sauerkraut: a rapid update on the pathophysiology and treatment of gastro-oesophageal reflux disease
}

\author{
L Brand, SF Steyn, DW Wolmarans
}

Centre of Excellence for Pharmaceutical Sciences, Department of Pharmacology, Faculty of Health Sciences, North-West University, South Africa

Corresponding author, email: dewet.wolmarans@nwu.ac.za

Gastro-oesophageal reflux disease: a brief pathophysiological background

Gastro-oesophageal reflux disease (GERD), in layman's terms known as heartburn, is a condition characterised by frequent oesophageal contact with gastric acid. Contrary to what is generally accepted, GERD is not caused by excessive quantities of gastric acid. Rather, symptoms result from any combination of a number of contributing factors, including decreased lower oesophageal sphincter pressure, hiatus hernia (where the stomach protrudes through the diaphragm), reduced oesophageal and gastric clearance and compromised oesophageal mucosa barrier integrity. ${ }^{1}$ Although most patients are able to manage GERD symptoms by means of lifestyle changes, chronic and recurrent episodes of reflux may result in erosive oesophagitis, nasal inflammation, dysphagia, i.e. difficulty in swallowing, and even pulmonary complications, e.g. asthma. ${ }^{2}$

Decreased lower oesophageal sphincter pressure can be caused by a number of factors, including diets rich in fats, cigarette smoking, and medication use. Further, apart from fatty meals, certain foods can have a direct influence on lower oesophageal sphincter pressure. These include citrus and tomato juice, coffee and overly spicy ingredients. ${ }^{1}$ Considering the oesophageal and gastric clearance rate, a frequent construct underlying the manifestation of GERD is increased contact time between the oesophageal epithelium and gastric content. As such, rapid clearance rates result in briefer periods of contact, which ultimately prevents reflux symptomology. Patient cohorts that are especially susceptible to reduced oesophageal clearance rates are overweight and obese individuals and those following a sedentary lifestyle, pregnant women, and the elderly. ${ }^{1}$ Although the oesophageal epithelium is not nearly as well protected against the erosive effects of gastric acid as the gastric epithelium itself, it does possess some innate protective mechanisms to prevent damage to especially the lower extremities of the oesophagus during brief periods of acidic exposure. These include acidneutralising bicarbonate secretion, mucus production and epithelial cell contact via tight junctions.
Due to the brief nature of this review, a more detailed dissection of GERD and its anatomical and physiological correlates is beyond the scope of the current work. Instead, we will focus on the therapeutic interventions as they are founded on the abovementioned aetiopathological mechanisms underlying the condition.

\section{The treatment of GERD}

\section{Lifestyle modification}

As alluded to earlier, a number of lifestyle factors can contribute to the manifestation of GERD-related symptoms. As such, patients, especially those presenting with infrequent symptom episodes only, may benefit from improvements in lifestyle. Interventions that can often be made without significant effort include moderate weight loss, changing sleeping posture so that the head is elevated relative to the position of the abdomen, avoiding tight fitting clothes and, if possible, smoking cessation. ${ }^{3,4}$ That said, since patients often resist engaging in substantial and significant lifestyle modification, the majority of individuals will need pharmacotherapy to ensure adequate symptom prevention and resolution.

\section{Pharmacotherapy}

The main objectives in the treatment of GERD are symptom relief, prevention of symptom relapse, healing of erosive oesophagitis and prevention of complications. ${ }^{5}$ Conventional pharmacological treatment strategies for GERD do not focus on the pathophysiology of GERD, but rather on establishing a less acidic reflux content to improve heartburn symptoms and provide the eroded mucosa in the distal oesophagus, if present sufficient time to heal. ${ }^{2}$ As such, acid-suppressing therapy is currently the mainstay of GERD treatment, with proton pump inhibitors (PPI) being superior to histamine-2 $\left(\mathrm{H}_{2}\right)$ antagonists in this regard. ${ }^{6,7}$ Alternative pharmacological therapies include prokinetics, transient lower oesophageal sphincter relaxation inhibitors (TLESR), and oesophageal mucosal nociceptor blockers. 
The proton pump inhibitors (PPIs)

Since their first introduction in the 1980s, PPIs have gradually become the backbone of acid reduction therapy. The PPIs act as irreversible blockers of the activated $\mathrm{H}^{+} / \mathrm{K}^{+}$-ATPase proton pump in the gastric parietal cells., 8 De to its relatively short half-life of 1-2 hours and considering that PPIs only bind to the activated form of the proton pumps in gastric parietal cells (in response to a meal), optimal acid suppression occurs when PPIs are administered 30-60 minutes prior to breakfast. However, once bound, the drug remains attached to the proton pump and is only cleared following the normal cell-specific degradation and replacement of the pump. This ensures a long-lasting effect, irrespective of their short half-life. That said, not all the parietal proton pumps are active during a single meal. As such, the efficacy of PPIs improves with subsequent dosing..$^{10}$ Omeprazole was the first in its class, with esomeprazole, lansoprazole, pantoprazole and rabeprazole currently on the South African market. Similar therapeutic efficacy (healing of erosive oesophagitis and achieving symptom control) is a shared characteristic among the different conventional PPIs. ${ }^{11,12}$ In patients who do not present with severe symptoms, e.g. signs of gastro-intestinal bleeding, weight loss, and dysphagia, an empiric PPI-trial is currently considered not only to be a cost-effective diagnostic tool, but also an efficient initial intervention for GERD. ${ }^{13}$ In both erosive GERD (ERD) and non-erosive reflux disease (NERD), complete symptom relief is reported in $72 \%$ of patients, whereas this number decreases to more or less $50 \%$ if there is no objective evidence of abnormal oesophageal acid exposure. ${ }^{14}$ In the event where patients experience extra-oesophageal manifestations of GERD (hoarseness, non-cardiac chest pain, coughing and asthma) as well as nocturnal GERD, symptoms may require twice daily PPI treatment ${ }^{4}$ as superior intragastric $\mathrm{pH}$ control is achieved with a twice daily omeprazole $20 \mathrm{mg}$ regimen compared to a once daily $40 \mathrm{mg}$ omeprazole dose. ${ }^{15}$ For the approximately one third of patients that fail to respond to an eight-week trial of a standard PPI dose, switching to another PPI or doubling the dose (given twice daily) are common therapeutic strategies. Further, PPI therapy can be combined with alginates and $\mathrm{H}_{2}$ antagonists for symptom relief; however, considering that PPIs are activated in an acidic environment, such strategies are to be used as a final resort only. Moreover, to overcome the concern of tolerance against the $\mathrm{H}_{2}$ antagonists, it is recommended that they are given on demand and/or intermittently. ${ }^{16}$ Prokinetics (see below), TLESRs and neuromodulators may also be used as add-on therapy, but the additional benefits are usually limited to subgroups of the population. ${ }^{17}$ The efficacy of PPIs, their low incidence of side-effects and good tolerability has led to their widespread long-term use (even without an appropriate indication), raising concerns regarding the consequences thereof. ${ }^{18}$ These concerns, including ischaemic heart and chronic kidney disease, bone fractures, community-acquired pneumonia, Clostridium difficile intestinal infection and dementia, are however, essentially founded on data from large association studies, rather than causal studies. ${ }^{19,20}$ To date, the evidence of serious adverse effects resulting from long-term PPI use is lacking. Indeed, appropriate use of PPIs is more important than the risk of side-effects and it is therefore recommended that physicians should keep prescribing these drugs in clinical conditions for which they are indicated. ${ }^{20}$ Some patients may benefit from intermittently administered, brief PPI courses (at least five days), given on demand if symptoms recur, ${ }^{9}$ but continuous long-term treatment is usually the standard of care for appropriately diagnosed and confirmed GERD. ${ }^{8,21}$ Importantly, as no tolerance with regard to the acid suppression effects of PPIs develops - as opposed to what is seen with histamine $\mathrm{H}_{2}$ receptor antagonists ${ }^{22,23}$ - patients that present with symptom exacerbation while being treated with PPIs should be referred to their medical practitioners for followup investigation.

\section{Histamine $\mathrm{H}_{2}$ receptor antagonists}

Cimetidine and ranitidine are competitive antagonists of the parietal $\mathrm{H}_{2}$ receptors that primarily inhibit nocturnal gastric acid secretion. ${ }^{24}$ Post-prandial gastrin- or acetylcholineinduced gastric acid secretion is not effectively inhibited and attenuation of their antisecretory effects (tolerance) develops within two weeks of continuous twice daily administration. 22,24,25 Consequently, the $\mathrm{H}_{2}$ antagonists are not very effective in the treatment of GERD associated with postprandial reflux. ${ }^{21}$ Although bedtime $\mathrm{H}_{2}$ antagonists are sometimes used to treat nocturnal gastric acid breakthrough in patients already on a twice daily PPI regimen, ${ }^{26,27}$ controversy exists over its long-term efficacy due to the development of tolerance. ${ }^{17,28,29} \mathrm{H}_{2}$ antagonists are usually well tolerated, but may increase the risk of infections because of acid suppression. ${ }^{30}$ Recently, ranitidine was the focus of intense clinical scrutiny, due to carcinogenic concerns related to one of the ingredients in ranitidine formulations, i.e. N-nitrosodimethylamine (NDMA). As such, from 1 October 2019, the South African Health Products Regulatory Authority (SAHPRA) has advised South Africans to return any heartburn medicines that contain ranitidine to their pharmacies, while the marketing of ranitidine-containing products was banned with immediate effect.

\section{Antacids and alginates}

Antacids neutralise gastric acid after it is secreted and are useful for rapid and temporary symptom relief of mild, occasional heartburn; however, they are not effective in healing erosive oesophagitis.,31 Most antacids consist of combinations of aluminium and magnesium hydroxide, while some effervescent antacids also contain sodium bicarbonate. Calcium carbonate is the most potent antacid available. ${ }^{4}$ However, carbonatecontaining antacids are not recommended due to their carbon dioxide-generating effect, which results in flatulence and relaxation of the oesophageal sphincter. Although being costeffective and relatively safe, they are not free from risks and sideeffects (diarrhoea with magnesium-containing and constipation with aluminium-containing formulations). Alginate, an insoluble substance that increases the surface tension of the gastric liquid content, is sometimes included in antacid preparations to form a protective layer against oesophageal acid exposure ${ }^{32}$ and to displace the postprandial gastric acid pocket..$^{33}$ Such 
combinations were found to be more effective in improving GERD symptoms than antacids alone. ${ }^{34}$

\section{Prokinetics}

The objective of prokinetic agents in the treatment of GERD is to enhance lower oesophageal sphincter tone, improving oesophageal clearance and increasing gastric motility, thereby increasing the emptying rate of gastric contents ${ }^{35}$ and decreasing oesophageal exposure to gastric content. Examples of prokinetics include metoclopramide (lipophilic dopamine/ serotonin receptor antagonist), domperidone (hydrophilic dopamine receptor antagonist), bethanechol (muscarinic receptor agonist), erythromycin (macrolide with motilin receptor agonist effects) and baclofen $\left(\mathrm{GABA}_{\mathrm{B}}\right.$ receptor agonist). ${ }^{36}$ Of these, baclofen is associated with the most favourable side-effect profile, especially in paediatric patients. ${ }^{36}$ Nevertheless, baclofen therapy used in combination with a PPI, could in fact result in greater side-effect risk. ${ }^{37}$ In turn, the central nervous system activity of metoclopramide limits its use, with the peripheral dopaminergic agonist, domperidone, considered as alternative. Importantly, domperidone is currently not FDA-approved for the treatment of GERD, ${ }^{38}$ probably because of its limited efficacy. ${ }^{39}$ The increasing awareness of antimicrobial resistance also limits the use of erythromycin (and other macrolides) in the treatment of GERD. Regardless, the combination of a prokinetic agent with a PPI does not appear to have any significant clinical advantage over PPI monotherapy.9,37 Finally, although also being able to induce prokinetic effects, cisapride is no longer available because of its potential to induce heart rhythm abnormalities. ${ }^{36}$

\section{Potassium-competitive acid blocker}

Vonoprazan is a potassium-competitive acid blocker (P-CAB) that was approved for clinical use in Japan in $2014 .{ }^{40}$ Its mechanism of action involves competing with $\mathrm{K}^{+}$at the $\mathrm{H}^{+} / \mathrm{K}^{+}$-ATPase proton pump, thereby blocking $\mathrm{H}^{+}$secretion. ${ }^{41}$ The main advantages of vonoprazan over commonly-used PPIs include it being stable in an acidic environment, binding reversibly to both the active and resting phase of $\mathrm{H}^{+} / \mathrm{K}^{+}$-ATPase, and its slower dissociation rate from the binding site. As such, vonoprazan has a longer halflife than the PPIs in general and can be taken before or after a meal. Further, it demonstrates therapeutic benefit after a single dose..$^{40,41}$ Vonoprazan has produced comparable therapeutic outcome to PPI monotherapy, ${ }^{42}$ yet its efficacy in PPI-resistant $\mathrm{GERD}^{43,44}$ is what makes it an attractive treatment alternative to PPI-augmented therapy. Finally, the side-effect profile of vonoprazan is also considered acceptable (pending larger and future studies), with mild to moderate gastrointestinal-related side-effects, nasopharyngitis and headache most commonly reported, ${ }^{45}$ while a four to eight-week treatment period does not induce any significant liver function alterations. ${ }^{45}$

\section{Mucosal protectants}

Mucosal protectants can be used in severe cases of erosive oesophagitis. These include misoprostol, sucralfate and bismuth. However, they present with minimal therapeutic benefit in uncomplicated GERD or isolated heartburn episodes.' Further, with respect to misoprostol, which is prescribed in South African abortion drug regimens, its use for non-abortion-related indications is not advised due to the significant risk it poses to women of reproductive age.

\section{Conclusion}

In this review, we provided a rapid review of current literature pertaining to GERD. Although the mainstay of treatment for GERD in South Africa is still founded on PPIs, alternatives include lifestyle change, $\mathrm{H}_{2}$ antagonists and novel drugs, i.e. vonoprazan (not yet registered in South Africa). Although the widespread use of PPIs raised some concern in terms of safety, large-scale, retrospective meta-analyses failed to reveal any significant risk to patient safety.

\section{References}

1. Williams DB, Schade RR. Gastroesophageal reflux disease. In: Linn WD, Wofford MR, O'Keefe ME, Posey LM. Pharmacotherapy in Primary Care. New York: McGraw-Hill Medical; 2009: p. 135.

2. Kahrilas PJ, Shaheen NJ, Vaezi MF. American Gastroenterological Association Medical Position Statement on the management of gastroesophageal reflux disease. Gastroenterology. 2008;135(4):1383-1391.e5. https://doi.org/10.1053/j. gastro.2008.08.045.

3. Pandolfino JE, El-Serag $H B$, Zhang $Q$, et al. Obesity: a challenge to esophagogastric junction integrity. Gastroenterology. 2006;130(3):639-649. https://doi.org/10.1053/j.gastro.2005.12.016.

4. Lowe RC. Medical management of gastroesophageal reflux disease. GI Motility online. 2006.

5. Hrelja N, Zerem E. Proton pump inhibitors in the management of gastroesophageal reflux disease. Medical Archives. 2011;65(1):52.

6. Vela MF. Medical treatments of GERD: the old and new. Gastroenterology Clinics. 2014;43(1):121-133. https://doi.org/10.1016/j.gtc.2013.12.001.

7. Sigterman KE, Van Pinxteren B, Bonis PA, Lau J, Numans ME. Short-term treatment with proton pump inhibitors, $\mathrm{H} 2$-receptor antagonists and prokinetics for gastro-oesophageal reflux disease-like symptoms and endoscopy negative reflux disease. Cochrane Database of Systematic Reviews. 2013 May;(5): CD002095. https://doi.org/10.1002/14651858.CD002095.pub5.

8. Gyawali CP. Proton Pump inhibitors in gastroesophageal reflux disease: friend or foe. Current Gastroenterology Reports. 2017;19(9):46. https://doi.org/10.1007/ s11894-017-0586-5.

9. Iwakiri K, Kinoshita $Y$, Habu Y, et al. Evidence-based clinical practice guidelines for gastroesophageal reflux disease 2015. Journal of Gastroenterology. 2016;51(8):751-767. https://doi.org/10.1007/s00535-016-1227-8.

10. Strand DS, Kim D, Peura DA. 25 Years of proton pump inhibitors: a comprehensive review. Gut and Liver. 2017;11(1):27-37. https://doi.org/10.5009/ gnl15502.

11. Gralnek IM, Dulai GS, Fennerty MB, Spiegel BM. Esomeprazole versus other proton pump inhibitors in erosive esophagitis: a meta-analysis of randomized clinical trials. Clinical Gastroenterology and Hepatology. 2006;4(12):1452-1458. https://doi.org/10.1016/j.cgh.2006.09.013.

12. Ip $S$, Chung M, Moorthy $D$, et al. Comparative effectiveness of management strategies for gastroesophageal reflux disease: update. 2011.

13. Chen J, Brady P. Gastroesophageal reflux disease: pathophysiology, diagnosis, and treatment. Gastroenterology Nursing. 2019;42(1):20-28. https://doi. org/10.1097/SGA.0000000000000359.

14. Weijenborg PW, Cremonini F, Smout AJ, Bredenoord AJ. PPI therapy is equally effective in well-defined non-erosive reflux disease and in reflux esophagitis: a meta-analysis. Neurogastroenterology and Motility. 2012;24(8):747-57, e350. https://doi.org/10.1111/j.1365-2982.2012.01888.x.

15. Kuo B, Castell DO. Optimal dosing of omeprazole $40 \mathrm{mg}$ daily: effects on gastric and esophageal $\mathrm{pH}$ and serum gastrin in healthy controls. American Journal of Gastroenterology. 1996;91(8).

16. Kung $\mathrm{Y}-\mathrm{M}, \mathrm{Hsu} \mathrm{W}-\mathrm{H}, \mathrm{Wu} \mathrm{M}-\mathrm{C}$, et al. Recent advances in the pharmacological management of gastroesophageal reflux disease. Digestive Diseases and Sciences. 2017;62(12):3298-3316. https://doi.org/10.1007/s10620-017-4830-5. 
17. Wang YK, Hsu W-H, Wang SS, et al. Current pharmacological management of gastroesophageal reflux disease. Gastroenterology Research and Practice. 2013; 2013:983653. https://doi.org/10.1155/2013/983653.

18. Reimer C. Safety of long-term PPI therapy. Best Practice and Research Clinical Gastroenterology. 2013;27(3):443-454. https://doi.org/10.1016/j. bpg.2013.06.001.

19. Freedberg $D E$, Kim $L S$, Yang Y-X, The risks and benefits of long-term use of proton pump inhibitors: expert review and best practice advice from the American Gastroenterological Association. Gastroenterology. 2017;152(4):706-715. https:// doi.org/10.1053/j.gastro.2017.01.031.

20. Savarino $E$, Marabotto $E$, Zentilin $P$, et al. A safety review of proton pump inhibitors to treat acid-related digestive diseases. Expert Opinion on Drug Safety. 2018;17(8):785-794. https://doi.org/10.1080/14740338.2018.1497155.

21. Kinoshita $Y$, Ishimura $N$, Ishihara $S$. Advantages and disadvantages of long-term proton pump inhibitor use. Journal of Neurogastroenterology and Motility. 2018;24(2):182-196. https://doi.org/10.5056/jnm18001.

22. Qvigstad G, Waldum H. Rebound hypersecretion after inhibition of gastric acid secretion. Basic and Clinical Pharmacology and Toxicology. 2004;94(5):202-208. https://doi.org/10.1111/j.1742-7843.2004.pto940502.x.

23. Prichard PJ, Jones DB, Yeomans ND, et al. The effectiveness of ranitidine in reducing gastric acid-secretion decreases with continued therapy. British Journal of Clinical Pharmacology. 1986;22(6):663-668. https://doi. org/10.1111/j.1365-2125.1986.tb02955.x.

24. Komazawa $Y$, Adachi $K$, Mihara $T$, et al. Tolerance to famotidine and ranitidine treatment after 14 days of administration in healthy subjects without Helicobacter pylori infection. Journal of Gastroenterology and Hepatology. 2003;18(6):678-682. https://doi.org/10.1046/j.1440-1746.2003.03041.x.

25. McRorie JW, Kirby JA, Miner PB. Histamine2-receptor antagonists: rapid development of tachyphylaxis with repeat dosing. World Journal of Gastrointestinal Pharmacology and Therapeutics. 2014;5(2):57.

26. Xue S, Katz PO, Banerjee P, Tutuian R, Castell DO. Bedtime H2 blockers improve nocturnal gastric acid control in GERD patients on proton pump inhibitors. Alimentary Pharmacology and Therapeutics. 2001;15(9):1351-1356. https://doi. org/10.1046/j.1365-2036.2001.01050.x.

27. Adachi $\mathrm{K}$, Komazawa $\mathrm{Y}$, Mihara $\mathrm{T}$, et al. Administration of $\mathrm{H} 2$ receptor antagonist with proton pump inhibitor is effective for long-term control of refractory reflux esophagitis. Journal of Clinical Gastroenterology. 2004;38(3):297-298. https://doi. org/10.1097/00004836-200403000-00020.

28. Fackler WK, Ours TM, Vaezi MF, Richter JE. Long-term effect of H2RA therapy on nocturnal gastric acid breakthrough. Gastroenterology. 2002;122(3):625-632. https://doi.org/10.1053/gast.2002.31876.

29. Wang Y, Pan T, Wang Q, Guo Z. Additional bedtime H2-receptor antagonist for the control of nocturnal gastric acid breakthrough. Cochrane Database of Systematic Reviews. 2009 Oct 7;(4):CD004275. https://doi. org/10.1002/14651858.CD004275.pub3.

30. Eom C-S, Lee S-S. Risk of fracture and pneumonia from acid suppressive drugs. World Journal of Methodology. 2011;1(1):15. https://doi.org/10.5662/wjm. v1.i1.15.

31. Fletcher J, Wirz A, Young J, Vallance R, McColl KE. Unbuffered highly acidic gastric juice exists at the gastroesophageal junction after a meal. Gastroenterology. 2001;121(4):775-783. https://doi.org/10.1053/gast.2001.27997.
32. Savarino $E$, Zentilin $P$, Marabotto $E$, et al. A review of pharmacotherapy for treating gastroesophageal reflux disease (GERD). Expert opinion on pharmacotherapy. 2017;18(13):1333-1343. https://doi.org/10.1080/14656566.2 017.1361407

33. Rohof WO, Bennink RJ, Smout AJ, Thomas E, Boeckxstaens GE. An alginateantacid formulation localizes to the acid pocket to reduce acid reflux in patients with gastroesophageal reflux disease. Clinical Gastroenterology and Hepatology. 2013;11(12):1585-1591. https://doi.org/10.1016/j.cgh.2013.04.046.

34. Leiman DA, Riff BP, Morgan $S$, et al. Alginate therapy is effective treatment for GERD symptoms: a systematic review and meta-analysis. Diseases of the Esophagus. 2017;30(5): 1. https://doi.org/10.1093/dote/dow020.

35. Vieira MC. Gastroesophageal reflux and prokinetics. In: Vandenplas Y. Gastroesophageal reflux in children: GER in Children. Springer; 2017. p. 313-320. https://doi.org/10.1007/978-3-319-60678-1_23.

36. Cohen S, Bueno de Mesquita M, Mimouni FB. Adverse effects reported in the use of gastroesophageal reflux disease treatments in children: a 10 years literature review. British Journal of Clinical Pharmacology. 2015;80(2):200-208. https://doi. org/10.1111/bcp.12619.

37. Ren LH, Chen WX, Qian LJ, et al. Addition of prokinetics to PPI therapy in gastroesophageal reflux disease: a meta-analysis. World Journal of Gastroenterology. 2014;20(9):2412-2419. https://dx.doi.org/10.3748/wjg.v20. i9.2412.

38. Li F, Pointer SD, Walker JP. Medical Management of GERD. In: Grams J, Perry KA, Tavakkoli A, editors. The SAGES Manual of Foregut Surgery. Springer; 2019. p. 147-160.

39. Maddern GJ, Kiroff GK, Leppard PI, Jamieson GG. Domperidone, metoclopramide, and placebo. All give symptomatic improvement in gastroesophageal reflux. Journal of Clinical Gastroenterology. 1986;8(2):135-140. https://dx.doi.org/10.3748/wjg.v20.19.2412.

40. Garnock-Jones KP. Vonoprazan: first global approval. Drugs. 2015;75(4):439-443. https://doi.org/10.1007/s40265-015-0368-z.

41. Otake $K$, Sakurai $Y$, Nishida $H$, et al. Characteristics of the novel potassiumcompetitive acid blocker vonoprazan fumarate (TAK-438). Advances in Therapy. 2016;33(7):1140-1157. https://doi.org/10.1007/s12325-016-0345-2.

42. Ashida K, Sakurai Y, Hori T, et al. Randomised clinical trial: vonoprazan, a novel potassium-competitive acid blocker, vs. lansoprazole for the healing of erosive oesophagitis. Alimentary Pharmacology and Therapeutics. 2016;43(2): 240-251. https://doi.org/10.1111/apt.13461.

43. Hoshino S, Kawami N, Takenouchi N, et al. Efficacy of vonoprazan for proton pump inhibitor-resistant reflux esophagitis. Digestion. 2017;95(2):156-161. https://doi.org/10.1159/000456072.

44. Shinozaki $\mathrm{S}$, Osawa $\mathrm{H}$, Hayashi $\mathrm{Y}$, et al. Vonoprazan $10 \mathrm{mg}$ daily is effective for the treatment of patients with proton pump inhibitor-resistant gastroesophageal reflux disease. Biomedical Reports. 2017;7(3):231-235. https://doi.org/10.3892/ br.2017.947.

45. Yang $X$, Li Y, Sun $Y$, et al. Vonoprazan: a novel and potent alternative in the treatment of acid-related diseases. Digestive Diseases and Sciences. 2018;63(2):302-311. https://doi.org/10.1007/s10620-017-4866-6. 